\title{
USULAN PERBAIKAN KUALITAS PRODUK PIPA API 5L PSL2 MENGGUNAKAN METODE SIX SIGMA
}

\author{
Ahmad Nalhadi, Nur Aida, Gina Ramayanti \\ Program Studi Teknik Industri, Fakultas Teknik, Universitas Serang Raya \\ Email: ahmadirqi02@gmail.com; aidan7803@gmail.com; ginaramayanti@gmail.com
}

\begin{abstract}
Abstrak - Proses produksi pipa API 5L PSL2 pada Perusahaan Pipa pada tahun 2017 terjadi $t$ produk defect sebesar $7 \%$. Hal ini masih diatas standar yang telah ditetapkan Perusahaan sebesar $4 \%$. Penelitian bertujuan untuk mengetahui nilai sigma dan memberikan rekomendasi perbaikan dengan metode six sigma. Berdasarkan hasil analisis DMAI didapat nilai level sigma pipa sebesar 3,65 dengan nilai DPMO 14448. Jenis kecacatan yang teridentifikasi pada proses seperti cacat open welding, high low, contact marking, scarfing, dan under dimension. Usulan perbaikan dilakukan dengan perancangan rekomendasi perbaikan menggunakan $5 \mathrm{~W}+1 \mathrm{H}$ dengan melakukan pemeriksaan kondisi mesin forming serta pergantian komponen bearing sebelum waktu lifetime bearing, melakukan preventive maintenance setiap satu minggu dan menambah semburan pendingin pada cutting tool.
\end{abstract}

Kata kunci: Defect, DPMO, Six Sigma

\begin{abstract}
The production process of API 5L PSL2 pipes in Pipe Companies in 2017 happened to defect products at $7 \%$. This defect is still above the standards set by the Company at $4 \%$. The study aims to determine the value of sigma and provide recommendations for improvement with the six sigma method. Based on the results of the DMAI analysis, the amount of the pipe sigma level was 3.65 with the value of DPMO 14448. Types of defects identified in the process such as open welding defects, high lows, contact marking, scarring, and under dimension Proposed improvements were made by designing recommendations for improvements using $5 \mathrm{~W}+1 \mathrm{H}$ by checking the condition of the forming machine and changing bearing components before the bearing lifetime, performing preventive maintenance every week and adding coolant bursts to the cutting tool.
\end{abstract}

Keywords: Defect, DPMO, Six Sigma

\section{PENDAHULUAN}

Di era persaingan bebas seperti sekarang menuntut seluruh perusahaan untuk menghasilkan produk berkualitas yang diminati oleh konsumen dan mengelola proses produksi agar tetap berjalan secara efektif dan efisien. Produk yang dihasilkan perusahaan manufaktur dalam sebuah proses produksi seringkali tidak semuanya dapat mencapai standar kualitas yang sudah ditetapkan. Hal ini menunjukkan bahwa terjadi produk defect yang dapat tidak tercapainya target produksi sesuai jadwal yang telah ditentukan. Salah satu cara mempertahankan dan meningkatkan mutu produk adalah dengan memperbaiki proses produksi tersebut.

Sebuah perusahaan pipa di daerah Cilegon juga mengalami permasalahan cacat produk. Total produksi pipa pada WO pertama sebesar 499 pcs dengan total cacat sebanyak 43 pcs dan presentasi cacat yang dialami perusahaan yaitu sekitar $7 \%$, sedangkan toleransi cacat perusahaan adalah $4 \%$. Hal itu dapat terjadi karena pada saat proses pembentukkan bulatan pipa tidak terbentuk dengan sempurna seperti pipa menjadi oval, sisi kiri dan kanan pipa tidak presisi, kegagalan penyatuan kedua sisi pipa, dimensi pipa tidak sesuai dengan standar, yang akan menyebabkan terjadinya produk defect. Jika dibiarkan kondisi ini sangat merugikan perusahaan karena biaya produksi akan meningkat. Jika biaya produksi meningkat maka keuntungan yang diperoleh perusahaan menurun. Untuk itu perusahaan perlu meningkatkan standar kualitas yang berguna untuk mengurangi atau menekan terjadinya defect sehingga proses produksi mencapai zero defect. 
Salah metode yang biasa digunakan dalam meminimalkan cacat produksi adalah metode Six Sigma. Six sigma sebagai program kualitas juga sebagai tool untuk pemecahan masalah. Six sigma memiliki konsep menetapkan standar kualitas mencapai 3.4 per satu juta kemungkinan dengan level sigma yang bisa menjadi evaluasi kinerja bagi perusahaan. Di dalam penerapan six sigma faktor-faktor penyebab yang mempengaruhi defect pada produk dapat diketahui dengan tujuan mengurangi defect yang terjadi pada saat proses produksi dalam peningkatan kualitas (Kusumawati \& Fitriyeni, 2017)

Six Sigma merupakan metode yang terorganisir untuk mengurangi variasi dalam proses organisasi dengan menggunakan spesialis perbaikan, metode terstruktur, dan metrik kinerja dengan tujuan mencapai tujuan strategis (Schroeder, Linderman, Liedtke, \& Choo, 2008). Penerapan Six Sigma secara konsisten mampu menurunkan cacat yang terjadi di proses produksi yang berdampak pada peningkatan jumlah produksi (Nelfiyanti, Rani, \& Fauzi, 2018; Supriyadi, Ramayanti, \& Roberto, 2017). Aplikasi Six Sigma yang luas mampu mengartikulasikan manfaat Six Sigma yang disajikan dalam pengembalian keuangan dengan menghubungkan peningkatan proses dengan penghematan biaya (Kwak \& Anbari, 2006).

Penelitian ini bertujuan untuk mengetahui nilai sigma proses produksi pipa dan merekomendasikan perbaikan yang sebaiknya dilakukan untuk mengurangi cacat yang terjadi. Rekomendasi ini diharapakan menjadi pertimbangan kebijakan perusahaan dalam menyusun kebijakan peningkatan mutu untuk menurunkan cacat yang terjadi.

\section{METODE PENELITIAN}

Penelitian ini menggunakan tahapan Six Sigma berdasarkan data produksi dan data cacat proses produksi pipa API 5L PSL2 $012 \mathrm{~m}$ dengan nomor Work Order (WO) I-293 sampai I-345. Teknik pengumpulan data dengan cara tanya jawab dengan operator atau pegawai yang ada di lingkup proses produksi serta mendapatkan informasi apa saja penyebab terjadinya produk pipa pada umumnya dan khususnya pada bagian produksi

\section{Define}

Fase define merupakan langkah pertama dalam six sigma yang berkaitan dengan tujuan, batasan dan identifikasi masalah yang akan diselesaikan (Zare Mehrjerdi, 2011). Tujuan dari langkah ini adalah untuk mengidentifikasikan permasalahan secara jelas dan dampak permasalahan terhadap kepuasan pelanggan.

\section{Measure}

Measure merupakan pengukuran kinerja pada proses yang sedang berlangsung berdasarkan data-data yang ada. Tujuan tahapan ini adalah untuk mencari kemungkinan perbaikan kinerja yang bisa dilakukan. Dalam langkah ini hal hal yang harus dilakukan adalah memilih satu atau lebih Critical To Quality (CTQ), dan menetapkan rencana pengumpulan data dan melakukan validasi sistem pengukuran yang digunakan

\section{Analyze}

Tahapan analyze merupakan tahapan mencari penyebab-penyebab masalah yang menyebabkan defect atau masalah yang terjadi. Tools yang digunakan dalam tahapan ini adalah diagram pareto dan diagram sebab akibat.

\section{Improve}

Tahap improve terdiri merupakan proses rekomendasi tindakan perbaikan berdasarkan permasalahan yang terjadi. Tindakan perbaikan merupakan aspek penting dalam program peningkatan kualitas yang berhubungan dengan pencapaian target yang telah ditetapkan (Wulandari, Lubis, \& Yanuar, 2018). Alat analisis yang digunakan adalah tahapan ini adalah $5 \mathrm{~W}+$ $1 \mathrm{H}$.

\section{Control}

Tahapan control merupakan tahap pengukuran kinerja perbaikan yang telah dilakukan (Supriyadi, Ramayanti, \& Aditia, 2017). Diagram kontrol dipakai untuk memonitoring kinerja dan melakukan kontrol apabila ada kondisi yang berada di luar kendali (Hendradi, 2012).

\section{HASIL DAN PEMBAHASAN}

Pengolahan data menggunakan metode DMAI (Define, Measure, Analyze, Improve) pada pendekatan Six Sigma. Metode DMAI digunakan sebagai langkah untuk menyelesaikan permasalahan yang ada di perusahaan. Dengan menggunakan pendekatan six sigma diharapkan mampu memberikan perbaikan pada kecepatan waktu proses dan kualitas pada produk yang dihasilkan oleh perusahaan bisa mencapai keadaan ideal.

\section{Define}

Pada tahap Ini dilakukan identifikasi proses produksi pipa dengan menggunakan diagram SIPOC untuk mengetahui aliran informasi proses pembuatan pipa (Gambar 1). 


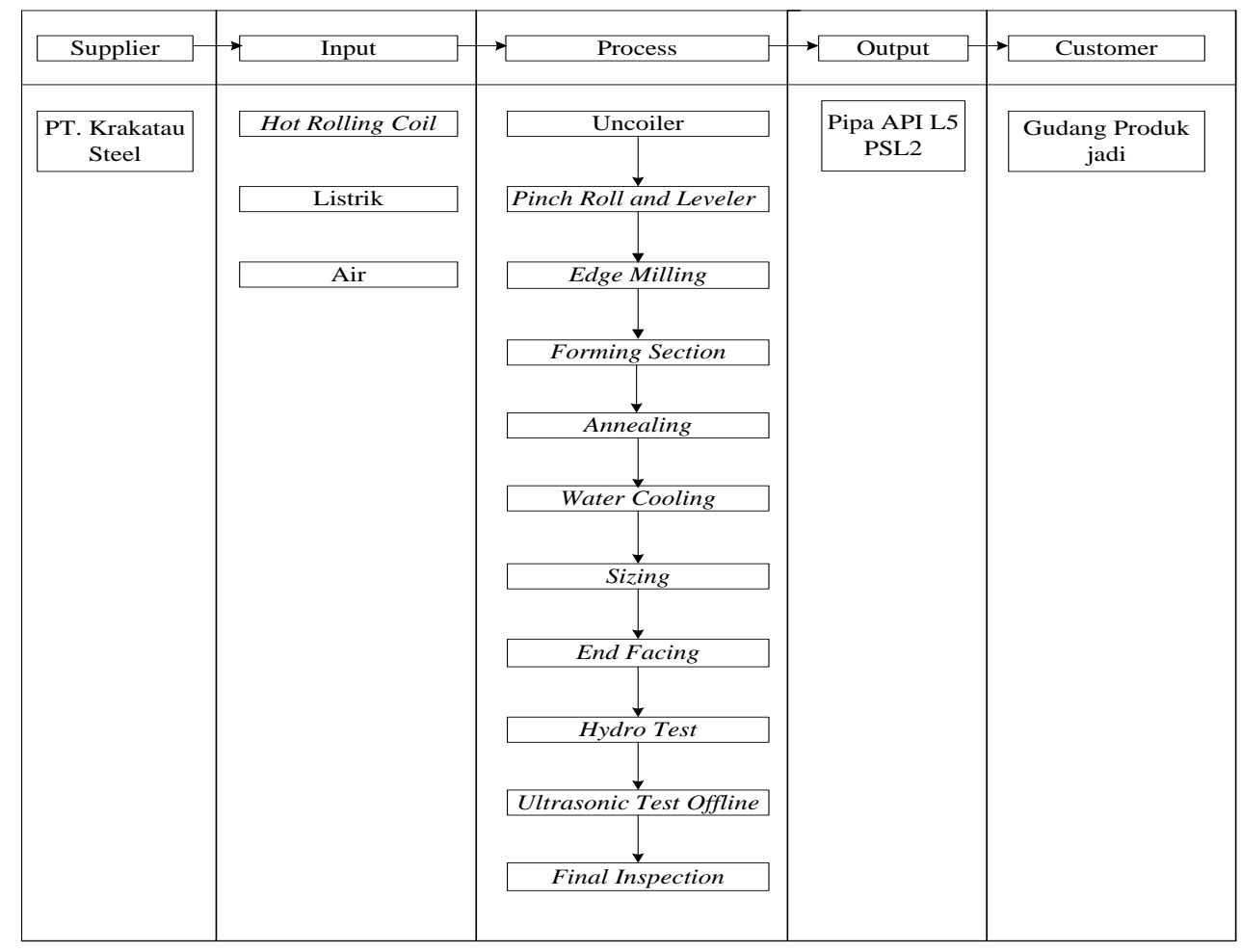

Gambar 4.3 Diagram SIPOC proses produksi pipa API 5L PSL2

Langkah selanjutnya adalah menentukan Critical To Quality (CTQ) data Defect pipa API $5 \mathrm{~L}$ PSL 2 dengan identifikasi defect produk adalah open welding, scarfing, contact marking, high-low, dan under dimension (tabel 1).

Tabel 1. Jenis defect pipa API 5L PSL2

\begin{tabular}{ll}
\hline Jenis Cacat & \multicolumn{1}{c}{ Keterangan } \\
\hline Open & $\begin{array}{l}\text { Kegagalan kedua sisi menyatu } \\
\text { dengan sempurna }\end{array}$ \\
Scarfing & $\begin{array}{l}\text { Penyerutan yang terlalu dalam } \\
\text { yang bisa membuat crack }\end{array}$ \\
Contact & $\begin{array}{l}\text { Adanya goresan pada pipa } \\
\text { marking }\end{array}$ \\
High- Low & $\begin{array}{l}\text { Kedua sisi kiri dan kanan pipa } \\
\text { tidak presisi }\end{array}$ \\
Under & $\begin{array}{l}\text { Dimensi yang tidak sesuai } \\
\text { Dimension }\end{array}$ \\
\hline
\end{tabular}

\section{Measure}

Pada tahap ini dilakukan perhitungan stabilitas pada proses produksi pipa pengukuran level sigma dan kapabilitas proses. Langkah pengukuran stabilitas proses ini berfungsi untuk mengetahui variasi pada proses pembuatan pipa yang dapat dilihat dari peta kendali. Pada grafik peta (Gambar 2) menunjukkan nilai proporsi cacat masih diatas nilai LCL dan dibawah nilai
UCL yang membuktikan proses yang ada masih terkendali.

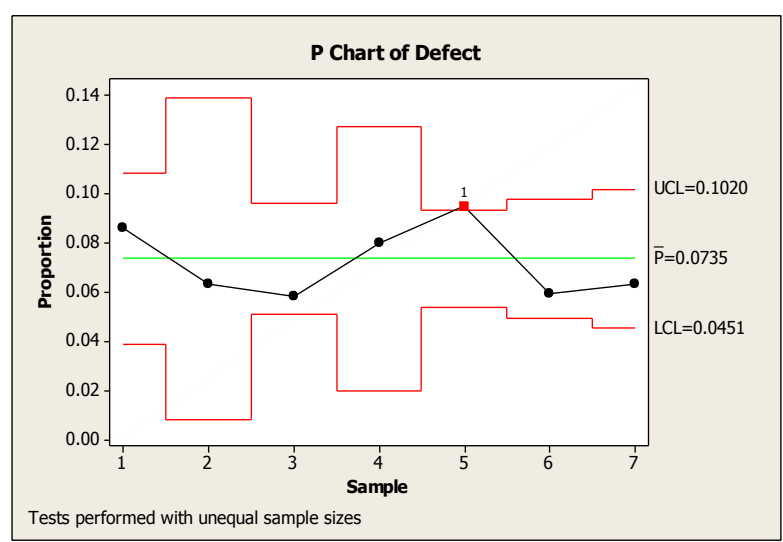

Gambar 2. Grafik Peta Kendali

Langkah selanjutnya adalah menentukan level sigma sesuai dengan data yang ada. Penentuan nilai ini berfungsi untuk meningkatkan level sigma setelah perbaikan yang dilakukan. Dari hasil perhitungan tingkat sigma yang diperoleh untuk produksi pipa API 5L PSL2 periode 2017 adalah 3.65 sigma, namun meskipun demikian masih perlu adanya perbaikan proses untuk meningkatkan nilai sigma perusahaan dengan mengukur kapabilitas proses pada produksi pipa API 5L PSL2 (tabel 2). 
Tabel 2. Data Perhitungan DPMO dan Nilai Sigma

\begin{tabular}{llccrrrc}
\hline \multirow{2}{*}{ No } & $\begin{array}{l}\text { No. } \\
\text { Wo }\end{array}$ & Total Porduksi & Defect & CTQ & DPO & DPMO & Level Sigma \\
\hline 1 & $1-293$ & 499 & 43 & 5 & 0.0172 & 17234.5 & 3.62 \\
2 & $1-312$ & 143 & 9 & 5 & 0.0126 & 12587.4 & 3.73 \\
3 & $1-326$ & 1216 & 71 & 5 & 0.0117 & 11677.6 & 3.71 \\
4 & $1-329$ & 212 & 17 & 5 & 0.0160 & 16037.7 & 3.61 \\
5 & $1-331$ & 1586 & 151 & 5 & 0.0190 & 19041.6 & 3.5 \\
6 & $1-344$ & 1024 & 61 & 5 & 0.0119 & 11914.1 & 3.7 \\
7 & $1-345$ & 759 & 48 & 5 & 0.0126 & 12648.2 & 3.71 \\
\hline JUMLAH & 5439 & 400 & 5 & 0.0144 & 14448.7 & 3.65 \\
\hline
\end{tabular}

Pada proses pengukuran kapabilitas terdapat dua jenis perhitungan data yaitu perhitungan kapabilitas sigma berdasarkan output kecacatan proses yang dihasilkan (CP) serta indeks kapabilitas proses yang digunakan untuk mengukur kemampuan proses dengan berdasarkan level sigma (cpk)

$$
\mathrm{Cp}=\frac{\text { Nilai Sigma }}{3}=\frac{3.65}{3}=1.2167
$$

Dari hasil perhitungan didapat nilai $\mathrm{Cp}$ sebesar 1.2167, angka yang diperoleh kurang dari 1.5 dapat diartikan bahwa akurasi dan spesifikasi proses masih rendah dari yang diharapkan.

\section{Analyze}

Pada tahap ini mengidentifikasi CTQ Dominan dengan menggunakan alat bantu diagram pareto kemudian diidentifikasi menggunakan diagram sebab akibat.

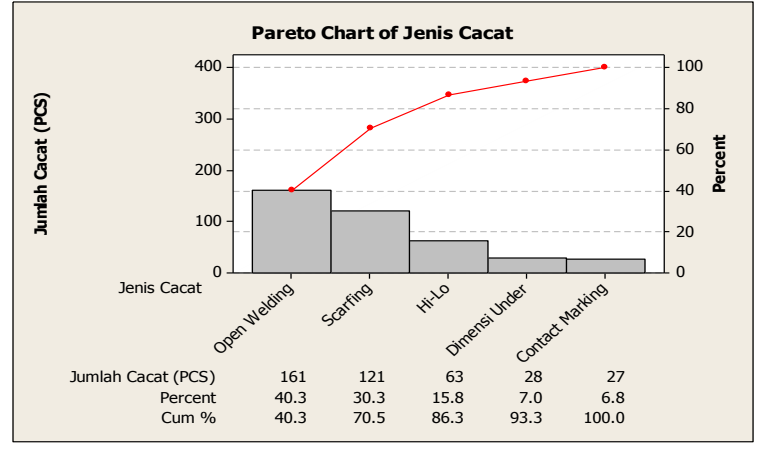

Gambar 3. Diagram Pareto Kecacatan Pipa API $5 \mathrm{~L}$

Dari diagram pareto (gambar 3), penyebab kecacatan ada 5 yaitu Open welding, Hi-Lo, Contact Marking, Scarfing, dan Diameter Under. 2 Penyebab paling besar tingkat kecacatannya yaitu Open Welding dengan persentase dari total kecacatan adalah $40.25 \%$, Scarfing dengan presentasi total kecacatan adalah $30.25 \%$.

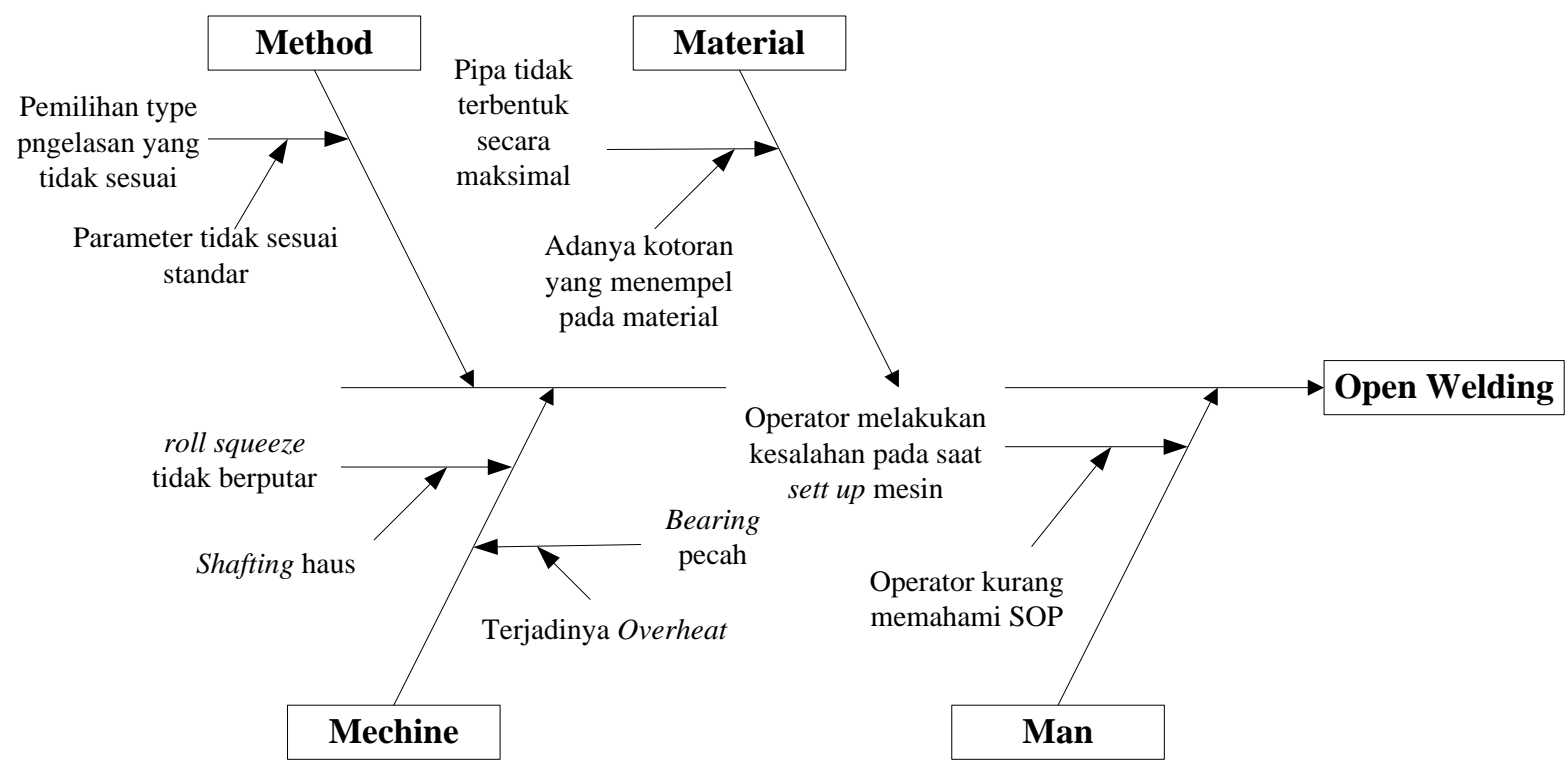

Gambar 4. Diagram sebab akibat kecacatan Open Welding 


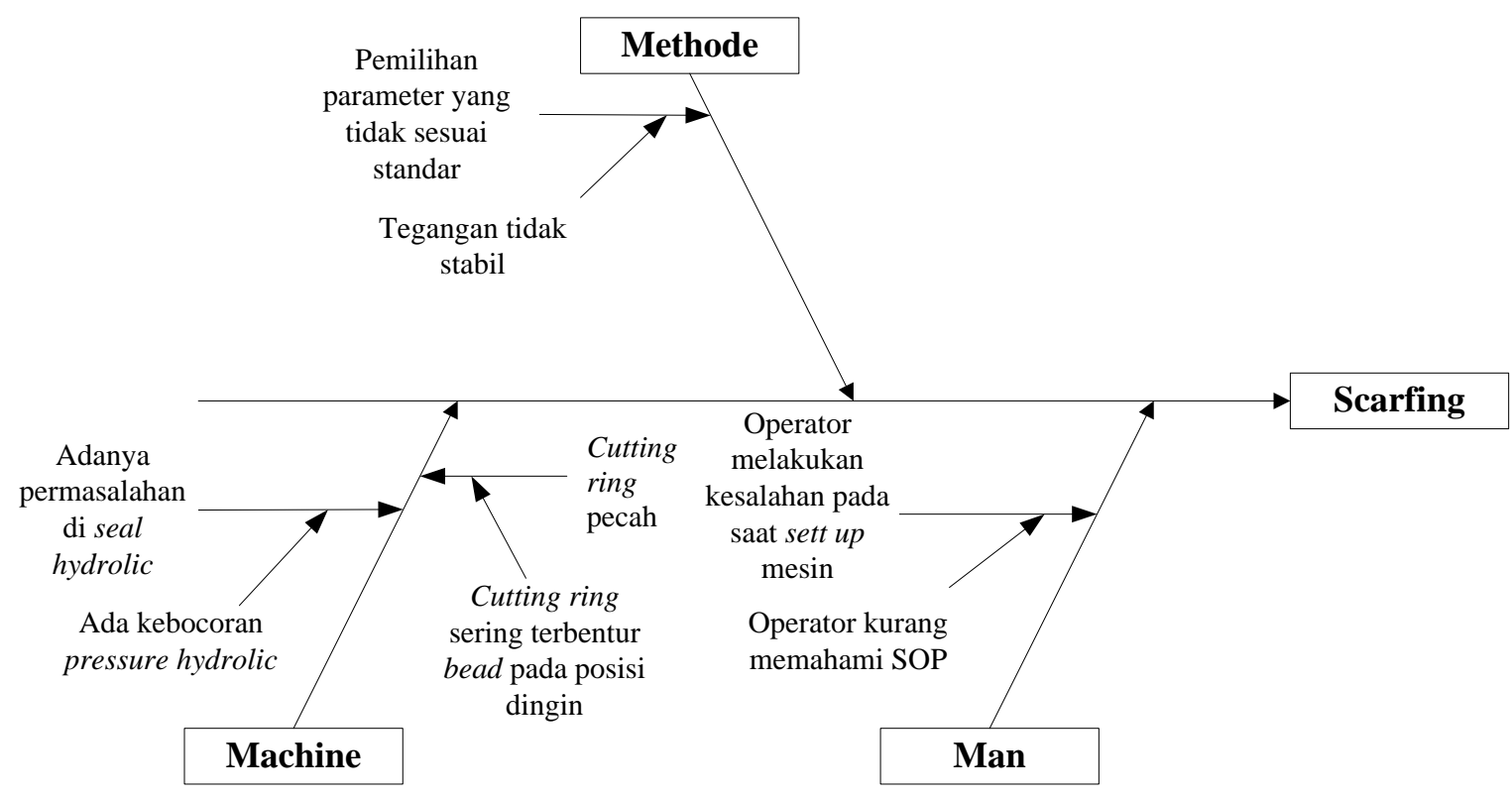

Gambar 5. Diagram sebab akibat kecacatan Scarfing

Setelah dilakukan analisis menggunakan diagram pareto kemudian dianalisis dengan menggunakan diagram sebab akibat untuk membantu mengidentifikasi penyebab suatu masalah terjadinya cacat open welding (Gambar 4) dan scarfing (Gambar 5).

Berdasarkan analisis dapat disimpulkan penyebab dari cacat open welding dari faktor manusia karena operator tidak memahami standar operasional kerja yang menyebabkan kinerja operator kurang maksimal. Dari faktor material karena teridentifikasi adanya kotoran yang menyebabkan pipa tidak dapat terbentuk secara sempurna pada saat proses pengelasan. Dari faktor metode yaitu pemilihan parameter yang tidak sesuai dan dari faktor mesin yaitu komponen bearing terjadi overheat yang membuat waktu lifetime bearing menjadi lebih cepat dan squeeze rool yang tidak berputar yang mengakibatkan fungsi squeeze roll tidak bekerja dengan baik dalam mengatur kesimetrisan pipa.

Penyebab cacat scarfing dari faktor manusia adalah operator kurang memahami standar operasional prosedur yang ada di perusahaan sehingga terjadinya kesalahan pada saat set up mesin sedangkan dari faktor metode pemilihan parameter yang tidak sesuai standar menyebabkan tegangan tidak stabil pada saat proses penyerutan sehingga bead yang terserut terlalu besar/kecil, dari faktor mesin cutting ring sering terbentur bead yang sudah dingin yang membuat cutting ring pecah dan kebocoran seal hydrolic yang membuat kinerja hydrolic tidak konsisten.

Setelah data disajikan dalam diagram sebab akibat kemudian dilakukan penentuan penyebab kritis dari cacat open welding dan cacat scarfing yang akan ditinjau dari aspek manusia, material, metode dan mesin dengan menggunakan Failure Mode and Effect Analysis (FMEA) (Tabel 3 dan Tabel 4).

Dari tabel FMEA (Tabel 3) dapat disimpulkan bahwa mode kegagalan terbesar pada cacat open welding yaitu pada bagian mesin dan komponen bearing yang memiliki nilai RPN tertinggi sebesar 391. Berdasarkan nilai RPN diatas perbaikan akan difokuskan pada komponen bearing dan roll squeeze tidak berputar dengan nilai RPN 294. Fokus perbaikan dalam cacat scarfing adalah pada bagian mesin yaitu cutting ring dan kebocoran hydrolic yang memiliki nilai RPN tertinggi sebesar 180.

\section{Improve}

Dari masing masing penyebab didapat nilai RPN tertinggi penyebab paling kritis untuk perbaikan mengurangi defect produk pipa, untuk kecacatan open welding yaitu bearing pecah dengan nilai RPN terhitung 392 dan roll squeeze tidak berputar dengan nilai RPN 294. Sedangkan cacat scarfing yaitu cutting ring yang pecah dan permasalahan kebocoran hydrolic dengan nilai RPN terhitung 180. Usulan perbaikan untuk meminimasi defect dirancang dari nilai RPN terbesar dengan merancang $5 \mathrm{~W}+1 \mathrm{H}$ (tabel 5 ). 
Tabel 3. Failure Mode and Effect Analysis (FMEA) Cacat Open Welding

\begin{tabular}{|c|c|c|c|c|c|c|c|c|}
\hline $\begin{array}{c}\text { Mode } \\
\text { Kegagalan } \\
\text { Potensial }\end{array}$ & $\begin{array}{c}\text { Efek } \\
\text { Kegagalan } \\
\text { Potensial }\end{array}$ & $\begin{array}{l}\text { Penyebab } \\
\text { Potensial }\end{array}$ & $\begin{array}{c}\text { Pengecekan } \\
\text { Saat Ini }\end{array}$ & $S$ & $\mathrm{O}$ & D & RPN & $\begin{array}{l}\text { Rekomendasi } \\
\text { Tindakan }\end{array}$ \\
\hline Man & $\begin{array}{l}\text { Kurangnya } \\
\text { sosialisasi } \\
\text { tentang } \\
\text { standar } \\
\text { prosedur } \\
\text { kerja }\end{array}$ & $\begin{array}{l}\text { Operator } \\
\text { melakukan } \\
\text { kesalahan } \\
\text { pada saat } \\
\text { set up mesin }\end{array}$ & $\begin{array}{l}\text { Memberikan } \\
\text { parameter } \\
\text { pegangan } \\
\text { yang sudah } \\
\text { pernah } \\
\text { dilakukan } \\
\text { untuk produksi } \\
\text { sebelumnya }\end{array}$ & 5 & 6 & 4 & 120 & \begin{tabular}{lr} 
- Memberikan & \\
pelatihan kerja & bagi operator \\
sebelum dilakukan \\
produksi untuk \\
settingan yang \\
tepat dan sesuai \\
\multicolumn{2}{c}{ dengan SOP }
\end{tabular} \\
\hline Material & $\begin{array}{l}\text { Ada } \\
\text { kotoran } \\
\text { yang } \\
\text { menempel } \\
\text { pada } \\
\text { material }\end{array}$ & $\begin{array}{l}\text { Pipa tidak } \\
\text { terbentuk } \\
\text { secara } \\
\text { maksimal }\end{array}$ & $\begin{array}{l}\text { Pengawasan } \\
\text { pada sisi } \\
\text { material yang } \\
\text { akan dilakukan } \\
\text { pengelasan } \\
\text { agar tetap } \\
\text { bersih }\end{array}$ & 5 & 6 & 6 & 180 & $\begin{array}{l}\text { - Memberikan alat } \\
\text { bantu (wire brush) } \\
\text { pada bagian } \\
\text { material yang akan } \\
\text { dilakukan } \\
\text { pengelasan } \\
\text { sehingga lebih } \\
\text { terjamin } \\
\text { kebersihannya }\end{array}$ \\
\hline Method & $\begin{array}{l}\text { Pemilihan } \\
\text { type } \\
\text { pengelasa } \\
\mathrm{n} \text { yang } \\
\text { sesuai }\end{array}$ & $\begin{array}{l}\text { Parameter } \\
\text { tidak sesuai } \\
\text { standar }\end{array}$ & $\begin{array}{l}\text { Memberikan } \\
\text { parameter } \\
\text { pegangan } \\
\text { yang sudah } \\
\text { pernah } \\
\text { dilakukan } \\
\text { untuk produksi } \\
\text { sebelumnya }\end{array}$ & 7 & 6 & 4 & 168 & $\begin{array}{l}\text { - Membuat list } \\
\text { parameter sesuai } \\
\text { dengan dimensi \& } \\
\text { spesifikasi pipa } \\
\text { yang akan } \\
\text { diproduksi }\end{array}$ \\
\hline Machine & $\begin{array}{l}\text { - roll } \\
\text { squeeze } \\
\text { tidak } \\
\text { berputar } \\
\text { - Bearing } \\
\text { pecah }\end{array}$ & $\begin{array}{l}\text { - Terjadinya } \\
\text { overheat }\end{array}$ & $\begin{array}{l}\text { Melakukan } \\
\text { penggantian } \\
\text { bearing sesuai } \\
\text { lifetime } \\
\text { bearing }\end{array}$ & 6 & 7 & 7 & 391 & $\begin{array}{l}\text { - Melakukan } \\
\text { preventive pada } \\
\text { bearing } \\
\text { greasing) agar } \\
\text { lifetime stabil } \\
\text { setiap waktu jeda } \\
\text { proses produksi }\end{array}$ \\
\hline
\end{tabular}


Tabel 4. Failure Mode and Effect Analysis (FMEA) Cacat Scarfing

\begin{tabular}{|c|c|c|c|c|c|c|c|c|}
\hline $\begin{array}{c}\text { Mode } \\
\text { Kegagalan } \\
\text { Potensial }\end{array}$ & $\begin{array}{c}\text { Efek } \\
\text { Kegagalan } \\
\text { Potensial }\end{array}$ & $\begin{array}{l}\text { Penyebab } \\
\text { Potensial }\end{array}$ & $\begin{array}{l}\text { Pengecekan } \\
\text { Saat Ini }\end{array}$ & $S$ & $\mathrm{O}$ & $\mathrm{D}$ & RPN & Rekomendasi Tindakan \\
\hline Man & $\begin{array}{l}\text { Kurangnya } \\
\text { sosialisasi } \\
\text { tentang } \\
\text { standar } \\
\text { prosedur } \\
\text { kerja }\end{array}$ & $\begin{array}{l}\text { Operator } \\
\text { melakukan } \\
\text { kesalahan } \\
\text { pada saat } \\
\text { set up } \\
\text { mesin }\end{array}$ & $\begin{array}{l}\text { Memberikan } \\
\text { parameter } \\
\text { pegangan } \\
\text { yang sudah } \\
\text { pernah } \\
\text { dilakukan } \\
\text { untuk } \\
\text { produksi } \\
\text { sebelumnya }\end{array}$ & 5 & 6 & 4 & 120 & $\begin{array}{l}\text { - Memberikan pelatihan } \\
\text { kerja bagi operator } \\
\text { sebelum } \\
\text { produksi untuk settingan } \\
\text { yang tepat dan sesuai } \\
\text { dengan SOP }\end{array}$ \\
\hline Method & $\begin{array}{l}\text { Tegangan } \\
\text { tidak stabil }\end{array}$ & $\begin{array}{l}\text { Pemilihan } \\
\text { parameter } \\
\text { yang tidak } \\
\text { sesuai } \\
\text { standar }\end{array}$ & $\begin{array}{l}\text { Memberikan } \\
\text { parameter } \\
\text { pegangan } \\
\text { yang sudah } \\
\text { pernah } \\
\text { dilakukan }\end{array}$ & 7 & 6 & 4 & 168 & $\begin{array}{l}\text { - Membuat list parameter } \\
\text { sesuai dengan dimensi \& } \\
\text { spesifikasi pipa yang akan } \\
\text { diproduksi }\end{array}$ \\
\hline \multirow[t]{3}{*}{ Machine } & $\begin{array}{l}\text { - Kebocor } \\
\text { an } \\
\text { hydrolic }\end{array}$ & $\begin{array}{l}\text { - Adanya } \\
\text { permasal } \\
\text { ahan di } \\
\text { seal } \\
\text { hydrolic }\end{array}$ & $\begin{array}{l}\text { mengontrol } \\
\text { pressure } \\
\text { hydrolic } \\
\text { melalui } \\
\text { pressure }\end{array}$ & 5 & 6 & 6 & 180 & $\begin{array}{lr}\text { - Melakukan preventive } \\
\text { maintenance dan } \\
\text { penggantian seal dan } \\
\text { komponen hydrolic secara } \\
\text { berkala }\end{array}$ \\
\hline & & & gauge & & & & & $\begin{array}{l}\text { - Mencari alat pengawas } \\
\text { (kamera) yang tahan } \\
\text { terhadap panas untuk } \\
\text { memantau arah serutan } \\
\text { pada bagian dalam pipa } \\
\text { serta bisa mendeteksi jika } \\
\text { ada kebocoran pada } \\
\text { sistem hydrolic }\end{array}$ \\
\hline & $\begin{array}{l}\text { - Cutting } \\
\text { ring } \\
\text { sering } \\
\text { terbentur } \\
\text { bead } \\
\text { yang } \\
\text { sudah } \\
\text { dingin }\end{array}$ & $\begin{array}{l}\text { - Cutting } \\
\text { ring } \\
\text { pecah }\end{array}$ & $\begin{array}{l}\text { Pergantian } \\
\text { cutting ring } \\
\text { sesuai } \\
\text { dengan life } \\
\text { time }\end{array}$ & 6 & 5 & 6 & 180 & $\begin{array}{l}\text { - Melakukan preventive } \\
\text { maintenance } \\
\text { menambah semburan } \\
\text { pendingin pada cutting } \\
\text { tool agar lebih banyak } \\
\text { sehingga lifetime lebih } \\
\text { stabil }\end{array}$ \\
\hline
\end{tabular}


Tabel 5. Tabel Usulan perbaikan dengan menggunakan 5W1H

\begin{tabular}{|c|c|c|c|c|c|c|c|}
\hline $\begin{array}{l}\text { Jenis } \\
\text { Cacat }\end{array}$ & $\begin{array}{l}\text { Penyebab } \\
\text { Potensial }\end{array}$ & $\begin{array}{l}\text { What } \\
\text { Ide }\end{array}$ & $\begin{array}{l}\text { Who } \\
\text { Siapa }\end{array}$ & $\begin{array}{c}\text { Why } \\
\text { Ukuran } \\
\text { Keberhasilan }\end{array}$ & $\begin{array}{c}\text { Where } \\
\text { Lokasi } \\
\text { Perbaikan }\end{array}$ & $\begin{array}{l}\text { When } \\
\text { Waktu }\end{array}$ & $\begin{array}{c}\text { Hwo } \\
\text { Cara } \\
\text { Penerapan }\end{array}$ \\
\hline Open & $\begin{array}{l}\text { Bearing } \\
\text { pecah }\end{array}$ & $\begin{array}{l}\text { Melakukan } \\
\text { pengecekan } \\
\text { dan } \\
\text { penggantian } \\
\text { bearing } \\
\text { sebelum waktu } \\
\text { lifetime }\end{array}$ & \multirow{4}{*}{$\begin{array}{c}\text { Petugas } \\
\text { maintena } \\
\text { nce }\end{array}$} & $\begin{array}{l}\text { Agar kerja } \\
\text { bearing bisa } \\
\text { maksimal dan } \\
\text { meminimasi } \\
\text { defect pada } \\
\text { produk }\end{array}$ & \multirow{4}{*}{$\begin{array}{l}\text { Mesin } \\
\text { forming }\end{array}$} & $\begin{array}{c}\text { Sebelum } \\
\text { waktu life } \\
\text { time } \\
\text { bearing }\end{array}$ & $\begin{array}{c}\text { Penggantian } \\
\text { Bearing } \\
\text { NUTR65150 } \\
\text { H }\end{array}$ \\
\hline Welding & $\begin{array}{l}\text { roll } \\
\text { squeeze } \\
\text { tidak } \\
\text { berputar }\end{array}$ & $\begin{array}{l}\text { Preventive } \\
\text { maintenance }\end{array}$ & & $\begin{array}{l}\text { Agar proses } \\
\text { pembentukan } \\
\text { pipa bisa } \\
\text { maksimal dan } \\
\text { meminimasi } \\
\text { defect pada } \\
\text { produk }\end{array}$ & & \multirow{3}{*}{$\begin{array}{l}\text { Setiap satu } \\
\text { minggu }\end{array}$} & \multirow{3}{*}{$\begin{array}{l}\text { Memeriksa } \\
\text { kondisi } \\
\text { mesin } \\
\text { forming serta } \\
\text { pengecekan } \\
\text { komponen }\end{array}$} \\
\hline & $\begin{array}{l}\text { Adanya } \\
\text { permasala } \\
\text { han di seal } \\
\text { hydrolic }\end{array}$ & $\begin{array}{l}\text { Preventive } \\
\text { maintenance }\end{array}$ & & $\begin{array}{l}\text { Agar proses } \\
\text { scarfing bisa } \\
\text { bekerja secara } \\
\text { maksimal }\end{array}$ & & & \\
\hline Scarfing & $\begin{array}{l}\text { Cutting } \\
\text { ring pecah }\end{array}$ & $\begin{array}{l}\text { Melakukan } \\
\text { preventive } \\
\text { maintenance \& } \\
\text { menambah } \\
\text { semburan } \\
\text { pendingin } \\
\text { pada cutting } \\
\text { tool }\end{array}$ & & $\begin{array}{l}\text { Agar proses } \\
\text { scarfing bisa } \\
\text { bekerja secara } \\
\text { maksimal dan } \\
\text { life time cutting } \\
\text { ring lebih stabil }\end{array}$ & & & \\
\hline
\end{tabular}

\section{KESIMPULAN}

Berdasarkan dari hasil analisis diperoleh kesimpulan bahwa nilai level sigma yang didapat adalah 3.65 dengan tingkat kecacatan sebesar $7 \%$ yang masih di atas toleransi cacat yang ditetapkan perusahaan $4 \%$. Jenis kecacatan yang teridentifikasi pada proses seperti cacat open welding, high low, contact marking, scarfing, dan under dimension. Usulan perbaikan dilakukan dengan perancangan rekomendasi perbaikan menggunakan $5 \mathrm{~W}+1 \mathrm{H}$ dengan melakukan pemeriksaan kondisi mesin forming serta pergantian komponen bearing sebelum waktu life bearing, melakukan perawatan mesin setiap satu minggu dan menambah semburan pendingin pada cutting tool.

\section{DAFTAR PUSTAKA}

Hendradi, T. C. (2012). Statistik six sigma dengan Minitab, Panduan Cerdas Inisiatif Kualitas. Yogyakarta: CV. Andi Offset.

Kusumawati, A., \& Fitriyeni, L. (2017). Pengendalian Kualitas Proses Pengemasan
Gula Dengan Pendekatan Six Sigma. Jurnal Sistem Dan Manajemen Industri, 1(1), 4348. https://doi.org/10.30656/jsmi.v1i1.173

Kwak, Y. H., \& Anbari, F. T. (2006). Benefits, obstacles, and future of six sigma approach. Technovation, 26(5-6), 708-715. https://doi.org/10.1016/j.technovation.2004. 10.003

Nelfiyanti, N., Rani, A. M., \& Fauzi, A. (2018). Implementasi Six Sigma untuk Perbaikan Kualitas Produk Kiwi Paste Berdasarkan Keluhan Pelanggan. Jurnal Sistem Dan Manajemen Industri, 2(1), 41-50. https://doi.org/10.30656/jsmi.v2i1.609

Schroeder, R. G., Linderman, K., Liedtke, C., \& Choo, A. S. (2008). Six Sigma: Definition and underlying theory. Journal of Operations Management, 26(4), 536-554. https://doi.org/10.1016/j.jom.2007.06.007

Supriyadi, S., Ramayanti, G., \& Aditia, Y. (2017). Analisa Kualitas Precious Slag Ball dengan Pendekatan Six Sigma. In Proceedings Seminar Ilmiah Nasional (pp. 45-58). 
Universitas Pamulang.

Supriyadi, S., Ramayanti, G., \& Roberto, A. C. (2017). Analisis Kualitas Produk dengan Pendekatan Six Sigma. In Prosiding SNTI dan SATELIT (2017) (pp. D7-D13). Malang: Jurusan Teknik Industri Universitas Brawijaya.

Wulandari, E. P., Lubis, M. Y., \& Yanuar, A. A. (2018). Usulan Perbaikan Untuk Meminimasi Defect Short Mold Pada Proses Peleburan Produk Grip Panjang Di Cv. Gradient Dengan Menggunakan Pendekatan Six Sigma. EProceedings of Engineering, 5(2), 481-488.

Zare Mehrjerdi, Y. (2011). Six-Sigma: methodology, tools and its future. Assembly Automation, 31(1), 79-88. https://doi.org/10.1016/j.ijpe.2009.01.003 